Research Article

\title{
Experimental Investigations on Charge Induction and Microseismic Characteristics of the Coal and Rock under Different Loading Rates
}

\author{
Yuchun Liu, ${ }^{1,2}$ Ling Ding, ${ }^{1}$ Yangfeng Zhao $\mathbb{D}^{1},{ }^{1}$ Yi Fan, ${ }^{1}$ and Hongfei Li $^{1}$ \\ ${ }^{1}$ Department of Mechanics \& Engineering, Liaoning Technical University, Fuxin 123000, China \\ ${ }^{2}$ College of Science, Liaoning Technical University, Fuxin 123000, China \\ Correspondence should be addressed to Yangfeng Zhao; zhyf_20010284@sina.com
}

Received 29 September 2021; Accepted 28 October 2021; Published 11 November 2021

Academic Editor: Xuesheng Liu

Copyright (c) 2021 Yuchun Liu et al. This is an open access article distributed under the Creative Commons Attribution License, which permits unrestricted use, distribution, and reproduction in any medium, provided the original work is properly cited.

\begin{abstract}
The research on charge induction and microseismic characteristics of coal and rock under different loading rates is of great significance for rockburst prediction. In this study, the coal and sandstone samples from the No. 11 mine of Pingdingshan Coal Mine are prepared. The charge induction and microseismic synchronous comprehensive monitoring system is built. The uniaxial compression tests of coal and sandstone samples under the different loading rates are conducted. The charge induction and microseismic signal characteristics in the deformation and fracture process of the coal and rock under the different loading rates are studied. The results show that, with the increase of loading rate, the compressive strength of the coal and rock samples increases and the time from the peak stress to instability failure becomes shorter. At the same loading rate, the softening failure stage time of coal is longer than that of sandstone. With the increase of loading rate, the duration of charge-induced signal and microseismic signal is longer and the events' number and amplitude of charge signal and microseismic signal increase in the deformation and fracture process of the coal and rock. Before the instability failure, the charge-induced signal and microseismic signal have both synchronous and asynchronous signals, and the amplitude of charge-induced and microseismic signals in each channel is different, which is related to the distance from the position of each sensor to the fracture point of the sample. During the instability failure, the charge induction and microseismic signals of each channel are generated synchronously, and the signal amplitude reaches the maximum values of $50 \mathrm{pC}$ and $6 \times 10^{-3} \mathrm{~m} / \mathrm{s}$ at the same time. With the increase of specimen stress, the dominant frequency of microseismic signals first increases and then decreases, while the amplitude of dominant frequency increases synchronously. The dominant frequency amplitude of microseismic signals is the largest in instability failure. With the increase of loading rate, the spectrum amplitude of microseismic signals changes little in the compaction stage, but the spectrum amplitude increases in other stages. At the same loading speed, the events' number of the microseismic signal of coal samples after peak stress is more than that of sandstone samples, and the signal amplitude is also larger. However, the spectrum distribution range of microseismic signals of coal samples is wider than that of sandstone samples, and the spectrum amplitude of coal samples is lower than that of sandstone. With the increase of loading rate, the time of the first generation of high-amplitude signals is advanced, and the stress of specimen becomes smaller when the first generation of high-amplitude signals occurs. With the increase of loading rate, the duration of microseismic and charge signal is longer, and the mean square amplitude of charge signal is larger.
\end{abstract}

\section{Introduction}

Rockburst is mine seismology, a grave natural disaster in the mine, and a dynamic destabilization phenomenon of the rock mass in coal mine induced by mining activities. With the increase of mining depth, the frequency, intensity, and scale of rockburst will rise. The loading rate effect caused by high-intensity excavation in deep mines often causes the collapse of the working face or surrounding rock and even induces rockburst [1-4]. When a rockburst occurs, the 
accumulated energy in the rock mass is released in the form of elastic energy, acoustic energy, thermal energy, and electromagnetic energy. The deformation and fracture process of coal and rock mass produces much physical information, such as charge, microseismic, and acoustic emission [5]. Therefore, the research on charge induction and microseismic characteristics of coal and rock under different loading rates is of great significance for rockburst prediction.

Researchers have performed extensive studies in the field of charge induction and microseismic monitoring of coal and rock deformation and fracture. Zhu et al. obtained the range of the crack tip electric quantity during rock deformation and fracture, and the total amount of charge depends on the number of cracks and the size and composition of rock samples [6]. Kuksenko et al. performed the loading tests on marbles and observed a significant increase of generated charge at the beginning of compression; it then gradually diminishes [7, 8]. Wang et al. conducted compression tests on coal samples and observed negative charges at the tensile areas around crack tip and positive charges at compression areas [9]. Zhao et al. studied charge signal characteristics of granite, sandstone and coal deformation and fracture using a noncontact, high magnification, and fast response charge sensor under uniaxial loading conditions $[2,5]$. Pan et al. studied the charge inducing regularity of coal rock at different loading rates in uniaxial compression tests; the charge induction law of gas bearing coal, the failure process at different confining pressure, and pore pressure under triaxial compression; and the charge induction law of coal and rock mass during tensile instability and failure [10-12]. He et al. studied the charge behaviours associated with the initiation and propagation of secondary cracks and the mechanical properties and the progressive failure of stressed rock samples [13]. The step functions on the curves of charge accumulation over time correspond to the fluctuation of stress, and a positive relationship between the crack face friction factors and the charge accumulation was included. $\mathrm{Li}$ et al. established an experimental system for collecting surface potential during the deformation and fracture of coal and concrete and studied the characteristic of the surface potential signal during the deformation and fracture of different specimens under uniaxial compression [14]. Li et al. studied the characteristics of the surface potential of coal under uniaxial compression and tensile fracture and carried out tests of the distribution law of strain field and surface potential of coal samples under load $[15,16]$. Yang et al. made rules of the surface potential of coal or rock and its variation law during the friction process [17]. Xu et al. studied the microseismic signals spectral characteristics of concrete and coal samples under uniaxial compression [18]. Yang systematically analyzed the strength, deformation, and microseismic characteristics of coal and rock [19]. Wang et al. revealed the rules of acoustic emission and microseismic effects of burst failure of compound coal-rock samples [20]. Li et al. conducted coal and rock vibration failure tests and observed the characteristics of microseismic signals of integral coal and rock specimens under different excitation acceleration and frequencies [21]. Zhu et al. obtained a microseismic dynamic response and characteristic analysis of coal and gas outburst experiment [22]. Zhao et al. built the multiparameter synchronous comprehensive monitoring system under uniaxial compression and studied microseismic, charge induction, self-potential, and acoustic emission characteristics during the fracture process of rocks [5]. In conclusion, the research on charge induction and microseismic signal characteristics of coal and rock under uniaxial compression at different loading rates has not been involved.

This paper attempts to perform the uniaxial compression tests on coal and rock samples under different loading rates by using the charge induction and microseism monitoring system. The goal is to study the charge induction and microseismic signal characteristics of coal and rock deformation and failure processes at different loading rates. This work may provide a reference for rockburst prediction.

\section{Charge Induction and Microseismic Behaviours of Coal and Rock}

2.1. Sample Preparation. The coal and sandstone samples are from Pingdingshan Coal Mine. The standard samples size is $\Phi 50 \mathrm{~mm} \times 100 \mathrm{~mm}$. The samples are dry, and the end face parallelism of their is controlled within $\pm 0.1 \mathrm{~mm}$. There are 24 coal and rock samples in total. The samples are divided into 6 groups, 4 in each group; Figure 1 shows the samples of coal and sandstone.

2.2. Experimental System. Figure 2 shows the experimental test system [13] used in this research, which included an MTS loading machine run in displacement control mode (Figure 2(a)), a charging signal shielding device (Figure 2(b)), and a signal collection system which simultaneously collects charge and microseismic signals (Figure 2(c)). A constant displacement rate was applied to the loading plate. The experiment loading rates were $0.005 \mathrm{~mm} / \mathrm{s}, 0.01 \mathrm{~mm} / \mathrm{s}$, and $0.05 \mathrm{~mm} / \mathrm{s}$. The charge and microseismic signal data acquisition system adopts a self-developed multichannel data collector with a maximum sampling frequency of $100 \mathrm{k}$ sps (samples per second), and the sampling frequency is $12.5 \mathrm{k} \mathrm{sps}$ in the experiment. The charge and microseismic signal acquisition system consists of the charge sensors, the microseismic sensors, $\mathrm{A} / \mathrm{D}$ converters, and a data acquisition unit. The charge sensor has a measurement range of $\pm 1.526 \times 10^{-15} \sim 5 \times 10^{-11} \mathrm{C}$. Its sensitivity is given as $A_{\mathrm{CQ}}=1 \times 10^{11} \mathrm{~V} / \mathrm{C}$. The sensor probes were placed on the shielding device at $5 \mathrm{~mm}$ away from the front, left, and right surfaces of the rock sample for detecting the charging development throughout the loading process. The charge sensor probes 1,2 , and 3 were connected to channels 1 , 2 , and 3 of the data collector, respectively. The microseismic sensor is a three-component sensor that is composed of one PS$10 \mathrm{~B}$ (vertical) and two PSH-10B (horizontal) speed sensors. The microseismic sensors 1,2 , and 3 were connected to channels 5,6 , and 7 of the data collector, respectively. The microseismic sensor has a measurement range of $\pm 6 \times 10^{-3} \mathrm{~m} /$ s. Its sensitivity is given as $22.7 \pm 5 \% \mathrm{~V} / \mathrm{m} / \mathrm{s}$. The microseismic sensor was pasted on the test bench with a coupling agent. 


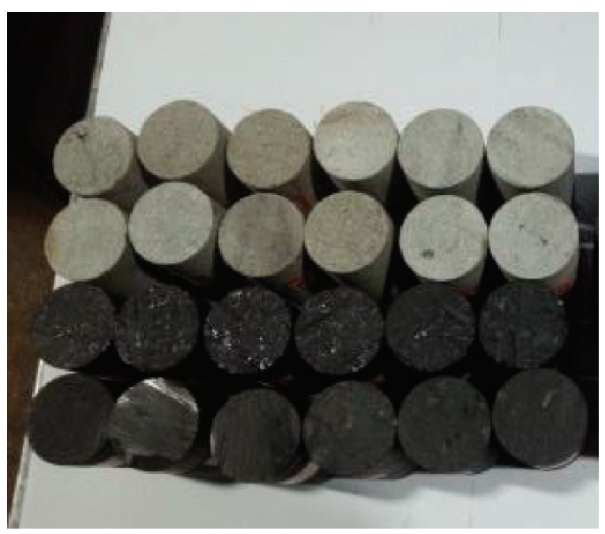

FIGURE 1: The samples of coal and sandstone.

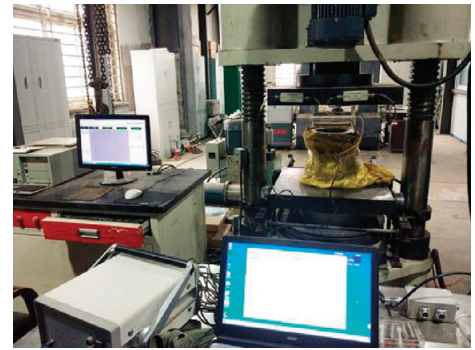

(a)

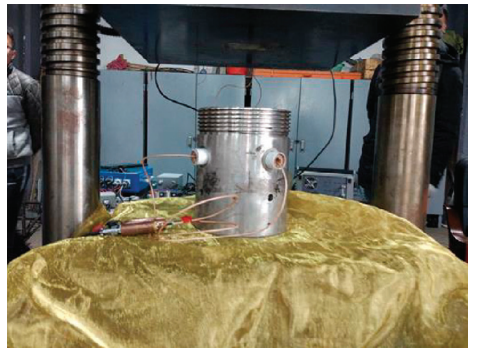

(b)

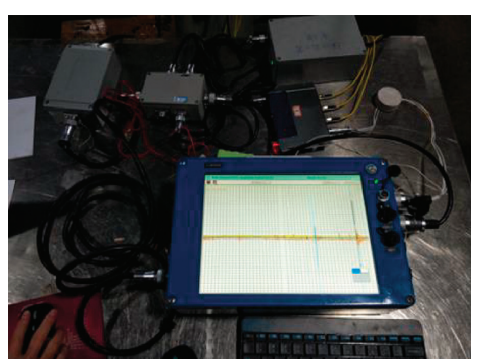

(c)

FIgURe 2: The uniaxial loading system [13]: (a) the loading machine and measuring system; (b) signal shielding device; (c) data collection system.

When the loading system and data acquisition system are timed on the network before the experiment, the time error is less than $10 \mathrm{~ms}$. The stress-strain curves, failure characteristics of the sample, and the progressive crack propagation were also captured by a camera and were compared with the detected charge and microseismic behaviours.

\section{Experimental Result Analysis}

In this study, six-group experiments of charge induction and microseismic signals were conducted in the deformation and fracture process of the coal and rock. Because of the similarity of the experimental results to the same type of rock samples, the representative monitoring data of charge induction and microseismic signals were selected as the study subjects. The monitoring data were processed to obtain the charge induction and microseismic signals behaviours of the deformation and fracture process of the coal and rock.

3.1. Mechanical Properties of the Coal and Rock Samples. Figure 3 shows the stress-strain curves of the coal and rock specimens under different loading rates. The compressive strength of sandstone is the lowest with the value of $20.2 \mathrm{MPa}$ when the loading rate is $0.005 \mathrm{~mm} / \mathrm{s}$. The first stress drop occurs when the specimen stress reaches $93.6 \% \sigma_{c}$. The postpeak softening stage of the specimen is gradually obvious. The instability failure duration is the longest. The reason for this is that the energy accumulation inside the specimen is slower under a low loading rate, and the release rate of accumulated energy after the peak is lower, its strain softening is more obvious, and the static splitting damage occurs in the specimen. The compressive strength of sandstone is $25.2 \mathrm{MPa}$ when the loading rate is $0.01 \mathrm{~mm} / \mathrm{s}$. The first stress drop occurs when the specimen stress reaches $65.5 \% \sigma_{c}$. Homogeneous splitting damage occurred in the specimen. The highest compressive strength of sandstone was $28.2 \mathrm{MPa}$ when the loading rate was $0.05 \mathrm{~mm} / \mathrm{s}$. The first stress drop occurs when the specimen stress reaches $58.5 \% \sigma_{c}$. The specimen is rapidly damaged with a strong burst after the stress reaches the peak stress. The specimen failure form is a significant brittle fracture. The comminuted ejection splitting damage occurred in the specimen crushing. As shown in Figure 3, the uniaxial compressive strength of coal and rock specimen increases with the increase of loading rate. The first stress drop is advanced, the postpeak softening stage gradually disappears, and its failure energy release rate increases with the increase of loading rate. The specimen damage type changes from local splitting damage to homogeneous splitting damage and comminuted ejection splitting damage. The deformation failure of coal and rock can be divided into four stages: compression-density stage, elastic stage, strengthening stage, and postpeak stage. The compressive strength of the coal sample is lower than that of sandstone. There is no obvious strengthening stage in coal sample, and there is an obvious strengthening stage in sandstone. The sandstone sample quickly destabilizes and destroys when the sample 


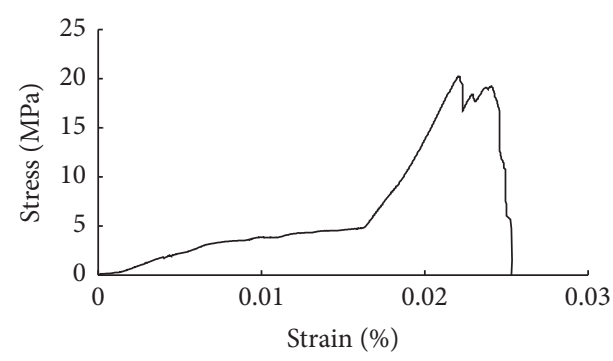

(a)

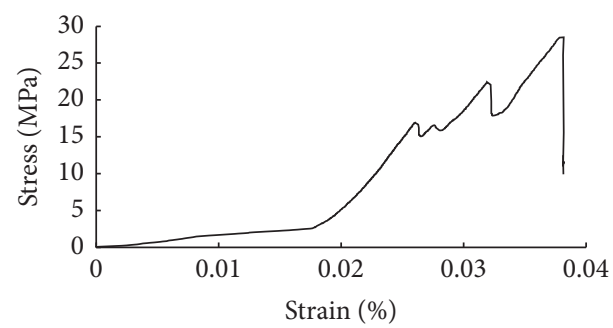

(c)

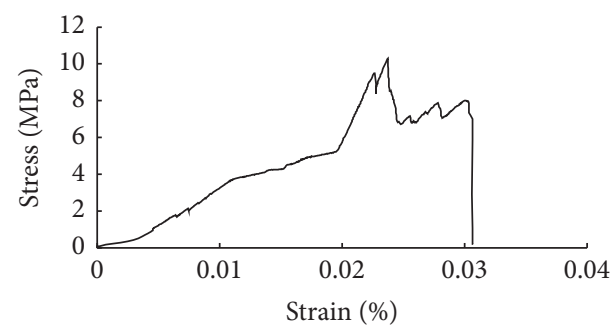

(e)

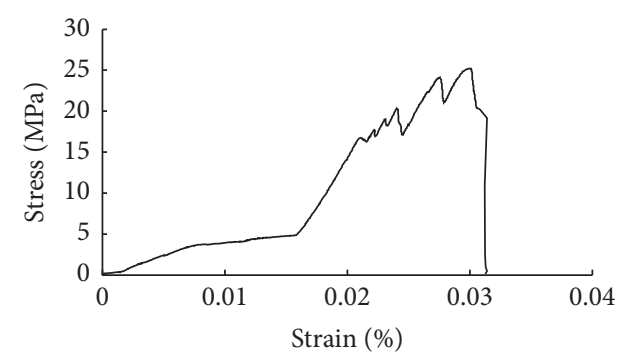

(b)

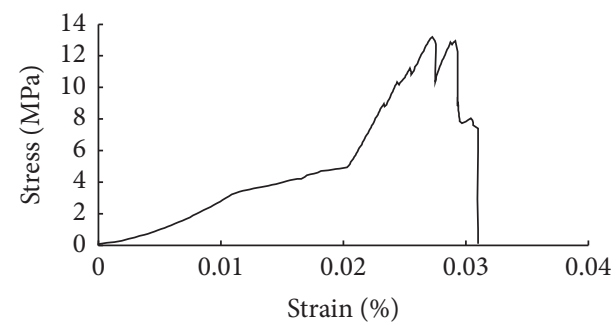

(d)

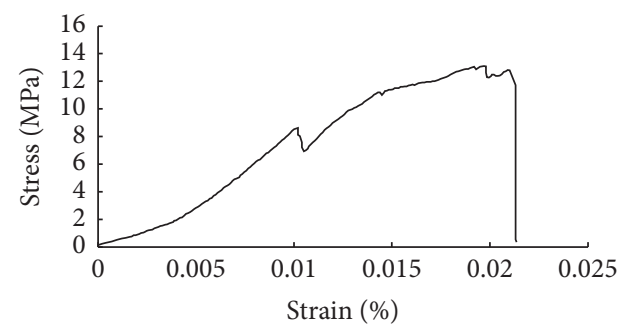

(f)

Figure 3: Stress-strain curves of the coal and rock specimens under different loading rates. (a) C1 sandstone with a loading rate of $0.005 \mathrm{~mm} / \mathrm{s}$. (b) C6 sandstone with a loading rate of $0.01 \mathrm{~mm} / \mathrm{s}$. (c) $\mathrm{C} 10$ sandstone with a loading rate of $0.05 \mathrm{~mm} / \mathrm{s}$. (d) A7 coal with a loading rate of $0.01 \mathrm{~mm} / \mathrm{s}$. (e) A3 coal with a loading rate of $0.005 \mathrm{~mm} / \mathrm{s}$. (f) A11 coal with a loading rate of $0.05 \mathrm{~mm} / \mathrm{s}$.

stress reaches the peak stress, while the coal sample has a strain-softening stage after the peak stress.

\subsection{Charge Induction and Microseismic Signals Characteristics.} Figure 4 shows the charge induction and microseismic signals of the deformation and fracture process of sandstone when the loading rate is $0.005 \mathrm{~mm} / \mathrm{s}$. Figure 5 shows the charge induction and microseismic signals of the deformation and fracture process of sandstone when the loading rate is $0.01 \mathrm{~mm} / \mathrm{s}$. Figure 6 shows the charge induction and microseismic signals of the deformation and fracture process of sandstone when the loading rate is $0.05 \mathrm{~mm} / \mathrm{s}$. Figure 7 shows the charge induction and microseismic signals of the deformation and fracture process of coal when the loading rate is $0.01 \mathrm{~mm} / \mathrm{s}$. The curves from top to bottom in the charge induction signal curve are the charge induction signals curves of channels 1,2, and 3, respectively. The curves from top to bottom in the microseismic signal curve are the microseismic signals curves of channels 5,6 , and 7 , respectively. The 6 channel signal is a vertical microseismic signal. The channel 5 and 7 signals are horizontal microseismic signals.

The charge induction signals of the sandstone specimen before the peak stress are very weak when the loading rate is $0.005 \mathrm{~mm} / \mathrm{s}$. The high-amplitude charge induction signals are generated when the specimen stress reaches the peak stress at $442.8 \mathrm{~s}$. The signal amplitude of channel 3 is $26.7 \mathrm{pC}$, of which the charge induction signal duration is $0.4 \mathrm{~s}$, while the channel 1 and 2 signal amplitudes are smaller than the channel 3 signal amplitude. The charge induction signal of small amplitude appeared at the second and third stress drops after the peak stress, and the maximum amplitude of its signals is $14.3 \mathrm{pC}$ and $10.5 \mathrm{pC}$, respectively. The maximum amplitude of the charge induction signal is generated before the instability failure of the sandstone specimen, the amplitude reaches $50 \mathrm{pC}$, and the signals are transient and paroxysmal. At the initial loading stage, the microseismic signals are generated when the sandstone specimen has a small stress drop at $80.3 \mathrm{~s}$ and $88.47 \mathrm{~s}$. The amplitudes of the microseismic signals are $2.2 \times 10^{-3} \mathrm{~m} / \mathrm{s}$ and $1.3 \times 10^{-3} \mathrm{~m} / \mathrm{s}$, but no charge signal is generated at this time. At the peak stress, there is a larger microseismic signal with an amplitude of $5.6 \times 10^{-3} \mathrm{~m} / \mathrm{s}$, and the signal duration is $2 \mathrm{~s}$. The microseismic signals and the charge induction signals are generated synchronously at this time.

The charge induction signals of the sandstone specimen in the linear elastic stage are very weak when the loading rate is $0.01 \mathrm{~mm} / \mathrm{s}$. The charge induction signals of high amplitude are first received when the specimen stress is $67 \% \sigma_{c}$ at the strengthening stage. The amplitude of the charge induction 


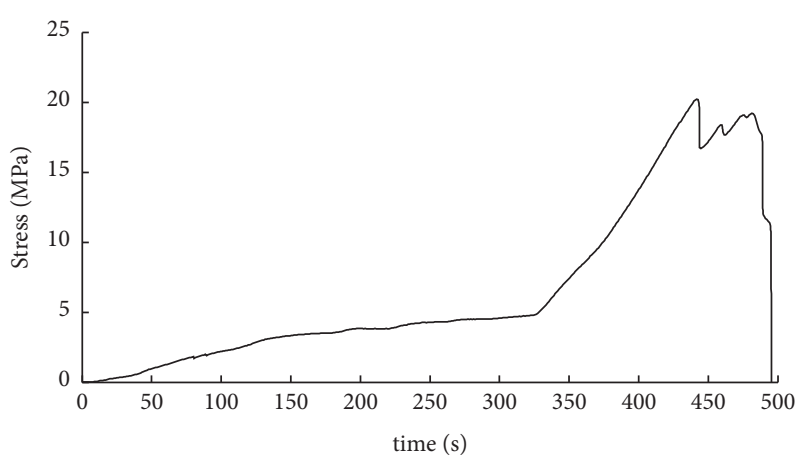

(a)

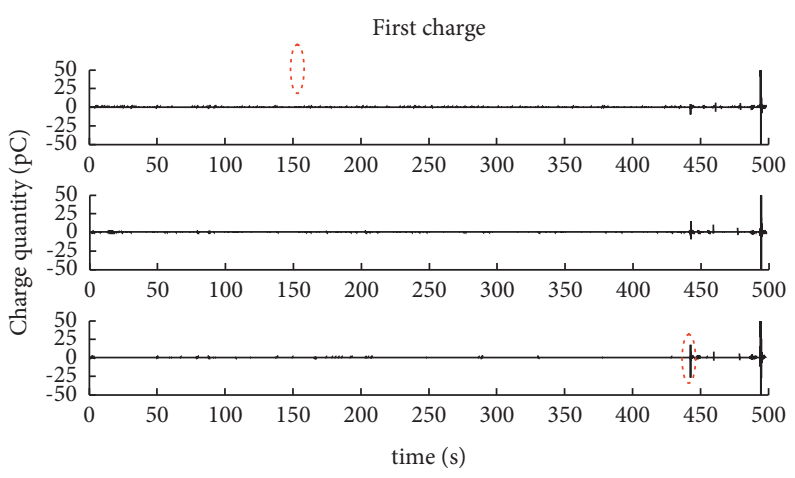

(b)

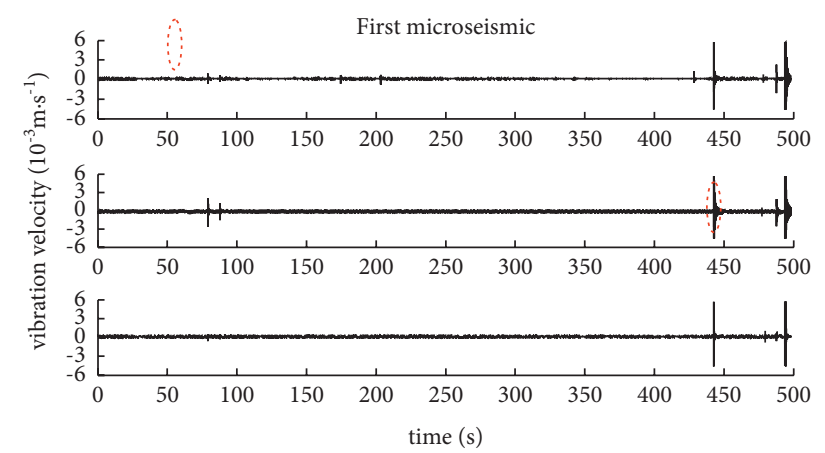

(c)

FIGURE 4: Charge induction and microseismic signals of sandstone when loading rate is $0.005 \mathrm{~mm} / \mathrm{s}$. (a) Stress curves. (b) Charge induction signals curves. (c) Microseismic signals curves.

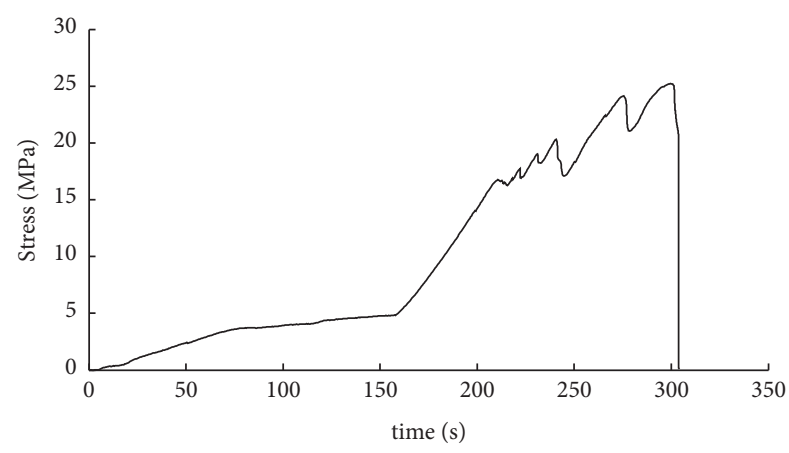

(a)

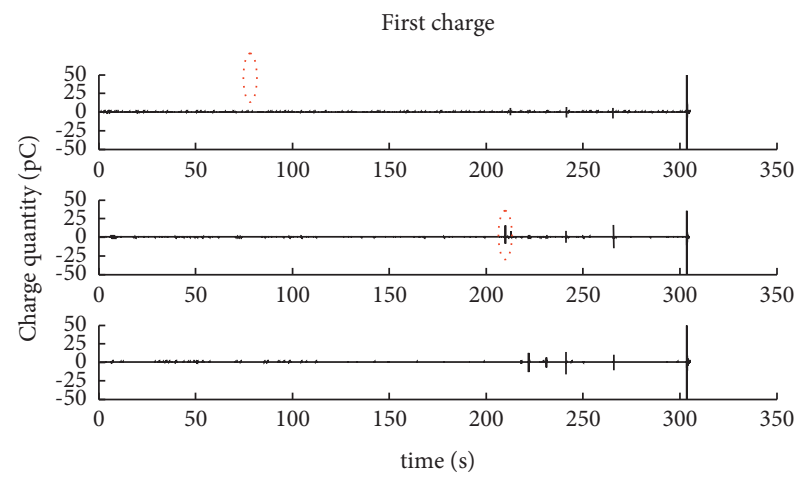

(b)

First microseismic

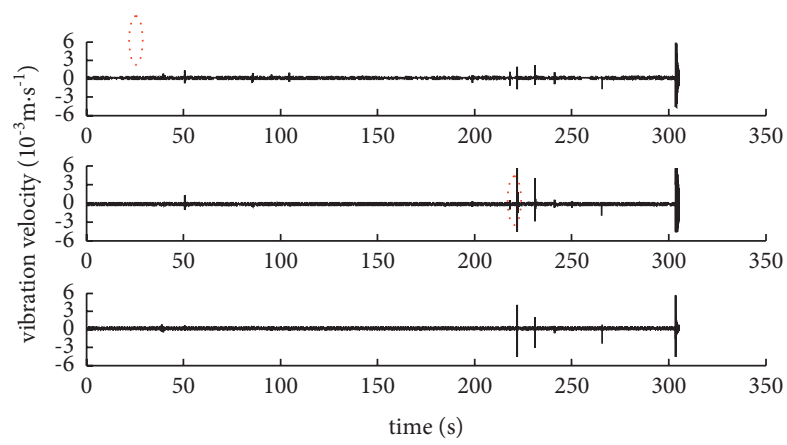

(c)

Figure 5: Charge induction and microseismic signals of sandstone when loading rate is $0.01 \mathrm{~mm} / \mathrm{s}$. (a) Stress curves. (b) Charge induction signals curves. (c) Microseismic signals curves. 


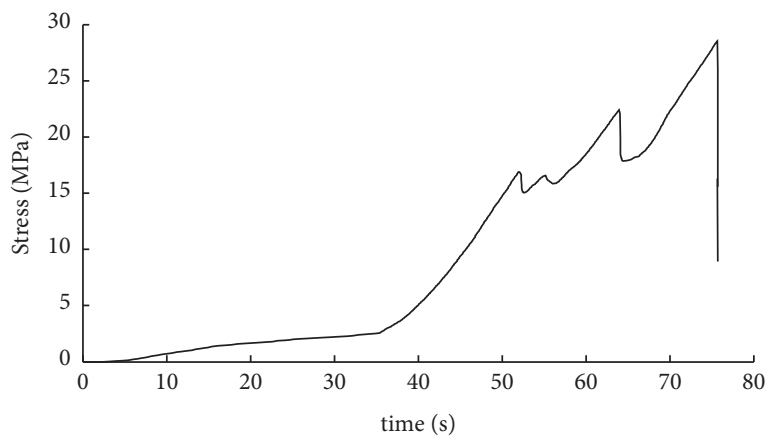

(a)

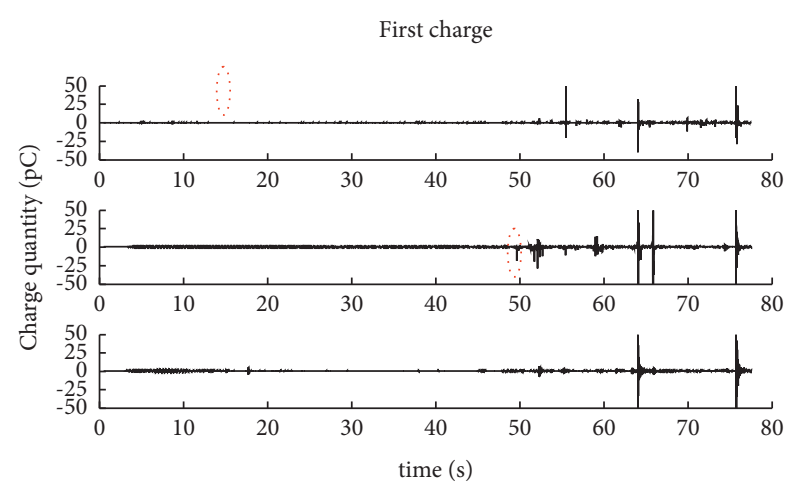

(b)

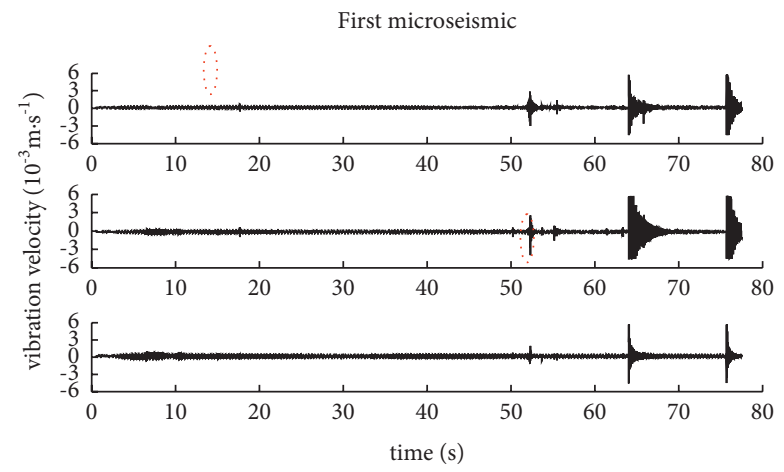

(c)

FIGURE 6: Charge induction and microseismic signals of sandstone when loading rate is $0.05 \mathrm{~mm} / \mathrm{s}$. (a) Stress curves. (b) Charge induction signals curves. (c) Microseismic signals curves.

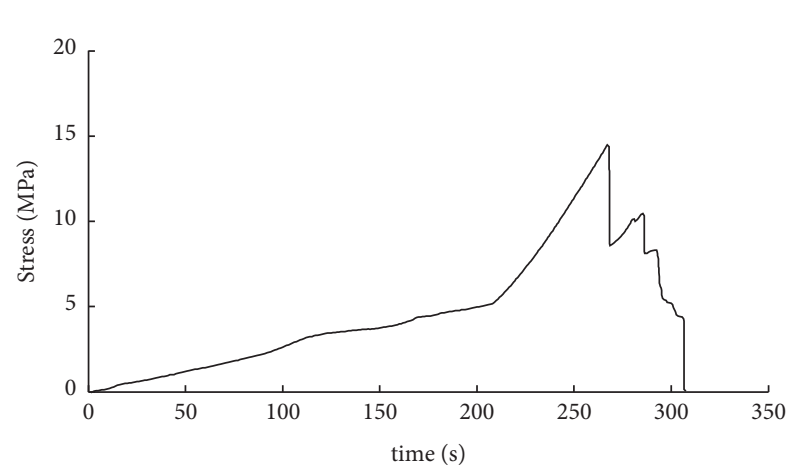

(a)

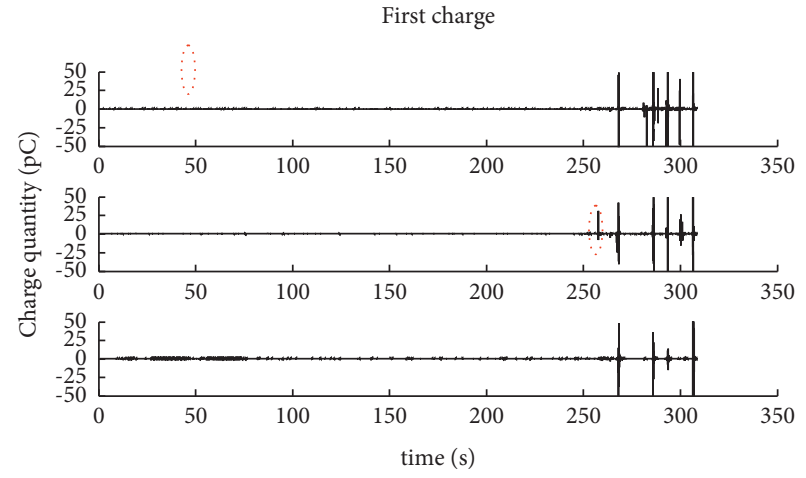

(b)

First microseismic

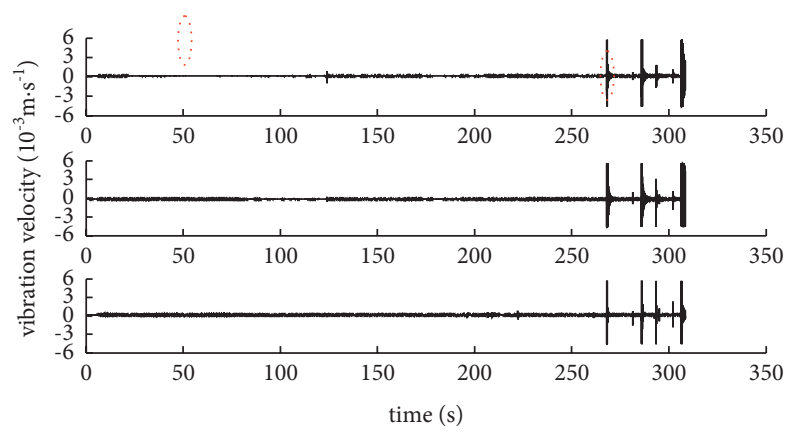

(c)

FIGURE 7: Charge induction and microseismic signals of coal when loading rate is $0.01 \mathrm{~mm} / \mathrm{s}$. (a) Stress curves. (b) Charge induction signals curves. (c) Microseismic signals curves. 
signal is $15.1 \mathrm{pC}$. The charge induction signals are generated when the specimen stress is $70.1 \% \sigma_{c}, 75.5 \% \sigma_{c}, 80.6 \% \sigma_{c}$, and $95.7 \% \sigma_{c}$, and the signal amplitude is $15 \mathrm{pC}, 10.2 \mathrm{pC}, 15.5 \mathrm{pC}$, and $28 \mathrm{pC}$, respectively. The maximum charge induction signal is generated at instability failure, and its amplitude is $50 \mathrm{pC}$. The microseismic signals are first received when the specimen stress is $9.6 \% \sigma_{c}$. The amplitude of the microseismic signal is $1.3 \times 10^{-3} \mathrm{~m} / \mathrm{s}$. At the end of the strengthening stage, the microseismic signals with high amplitude began to appear one after another. The synchronized signals of high amplitude occur at $221.6 \mathrm{~s}, 231.2 \mathrm{~s}$, and $275.5 \mathrm{~s}$, and their amplitudes are $5.62 \times 10^{-3} \mathrm{~m} / \mathrm{s}, \quad 3.95 \times 10^{-3} \mathrm{~m} / \mathrm{s}$, and $1.4 \times 10^{-3} \mathrm{~m} / \mathrm{s}$, where the microseismic small amplitude signals are more than the charge induction signals. The events' number of charge and microseismic signal increases during the strengthening stage.

The charge induction signals of the sandstone specimen in the linear elastic stage are very weak when the loading rate is $0.05 \mathrm{~mm} / \mathrm{s}$. The charge induction signals of high amplitude are first received when the specimen stress is $54.1 \% \sigma_{c}$ at the strengthening stage. The amplitude of the charge induction signal is $18.3 \mathrm{pC}$. A large stress drop produces when the specimen stress is $78.6 \% \sigma_{c}$. The high-amplitude synchronous signals are received by the 3 charge sensors at the same time. The amplitude of the charge induction signal is $50 \mathrm{pC}$. The microseismic signals of high amplitude are first received when the specimen stress is $59.3 \% \sigma_{c}$. The amplitude of the microseismic signal is $4.0 \times 10^{-3} \mathrm{~m} / \mathrm{s}$. Under different loading rates, there are microseismic signals and chargeinduced signals generated synchronously $0.1-0.3 \mathrm{~s}$ before instability failure of sandstone specimens. All signal amplitudes have reached the maximum. The microseismic signal amplitude is $6 \times 10^{-3} \mathrm{~m} / \mathrm{s}$. The charge induction signal amplitude is $50 \mathrm{pC}$.

For the sandstone specimens, there are weak charge induction and microseismic signals in the elastic stage. There are larger charge and microseismic signals in the strengthening phase because of microcracks generation and expansion. The number of charge induction and microseismic signal events increases significantly, and the signal amplitude also increases significantly in the instability failure stage because of cracks convergence and penetration. When there is a large stress drop in the specimen before the instability failure, there are larger charge induction signals in channels 1, 2, and 3. But the signal amplitude of each channel is different. The amplitude of the charge signals is larger when the sensor probe is close to the failure area of the specimen, and the failure of the specimen has a greater impact on the charge induction signal. In the instability failure damage, the crack expands rapidly, the energy is also released instantaneously, the load-bearing structural surface is rapidly instability failure, and the amplitudes of the charge induction and microseismic signals reach the maximum at the same time.

The charge induction signals of the coal specimen before the peak stress are very weak when the loading rate is $0.01 \mathrm{~mm} / \mathrm{s}$. The signal amplitude of channel 2 is $28.2 \mathrm{pC}$ when the coal sample stress is $90.3 \% \sigma_{c}$, while the microseismic signal is very weak. The stress drop of the coal sample at the peak stress is $6.82 \mathrm{MPa}$. The charge induction signal and microseismic signal are generated synchronously $0.1-0.3 \mathrm{~s}$ before the stress drop. The amplitude of the microseismic signals is $6 \times 10^{-3} \mathrm{~m} / \mathrm{s}$. The amplitude of the charge induction signals is $50 \mathrm{pC}$. The synchronous charge induction and microseismic signals appear several times after the peak stress of the coal sample, and the amplitude reaches the maximum value of $50 \mathrm{pC}$ and $6 \times 10^{-3} \mathrm{~m} / \mathrm{s}$. Of course, there are also some nonsynchronous signals in the charge induction and microseismic signals. The comparison between Figure 7 and Figures 4-6, the comparison of charge induction and microseismic signals in the deformation and fracture process of coal samples and sandstone samples, shows that the signals of coal samples and sandstone samples have similar laws in the prepeak stage. The charge induction and microseismic signals are weak. However, in the postpeak stage, the events' number of charge induction and microseismic signal of coal samples is more than that of sandstone samples, which is due to the greater degree of failure and more friction on fracture surfaces in coal samples.

In summary, the compressive strength of coal and rock increases with the increase of loading rate. The stress decreases when the specimens are in the strengthening damage stage. In the strengthening damage stage, the stress growth rate of the specimen accelerates. The time from the peak stress to instability failure of the specimen becomes shorter, and the strain becomes smaller. At the same loading speed, the postpeak softening failure stage of coal lasts longer than that of sandstone. The coal samples are destroyed quickly when the stress reaches the peak stress at the loading rate of $0.05 \mathrm{~mm} / \mathrm{s}$, while the sandstone is destroyed quickly when the stress reaches the peak stress at the loading rate of $0.01 \mathrm{~mm} / \mathrm{s}$. The time of the first obvious electric charge and microseismic signals for the coal and rock advances with the increase of loading rate. After that, the quiet period of the signals is shortened, the charge-induced signal transits from paroxysmal to continuous, and the duration of microseismic signal is prolonged. The events' number and the amplitude of charge signal and microseismic signal increase. Before the instability failure, the charge-induced signal and microseismic signal have both synchronous and asynchronous signals, and the amplitude of charge-induced and microseismic signals in each channel is different, which is related to the distance from the position of each sensor to the fracture point of the sample. During instability, the charge induction and microseismic signals of each channel are generated synchronously, and the signal amplitude reaches the maximum values of $50 \mathrm{pC}$ and $6 \times 10^{-3} \mathrm{~m} / \mathrm{s}$ at the same time.

Microseism is a phenomenon in which energy is released in the form of stress waves in areas of localized deformation and fracture under external loading of the coal rock. In contrast, charge induction is caused by fracture tip discharge, frictional generation of electricity by misalignment of the joint surface, and the piezoelectric effect of the piezoelectric material itself. In terms of the mechanism of charge induction and microseismic signal characteristics generation, the mechanism of charge signal generation 

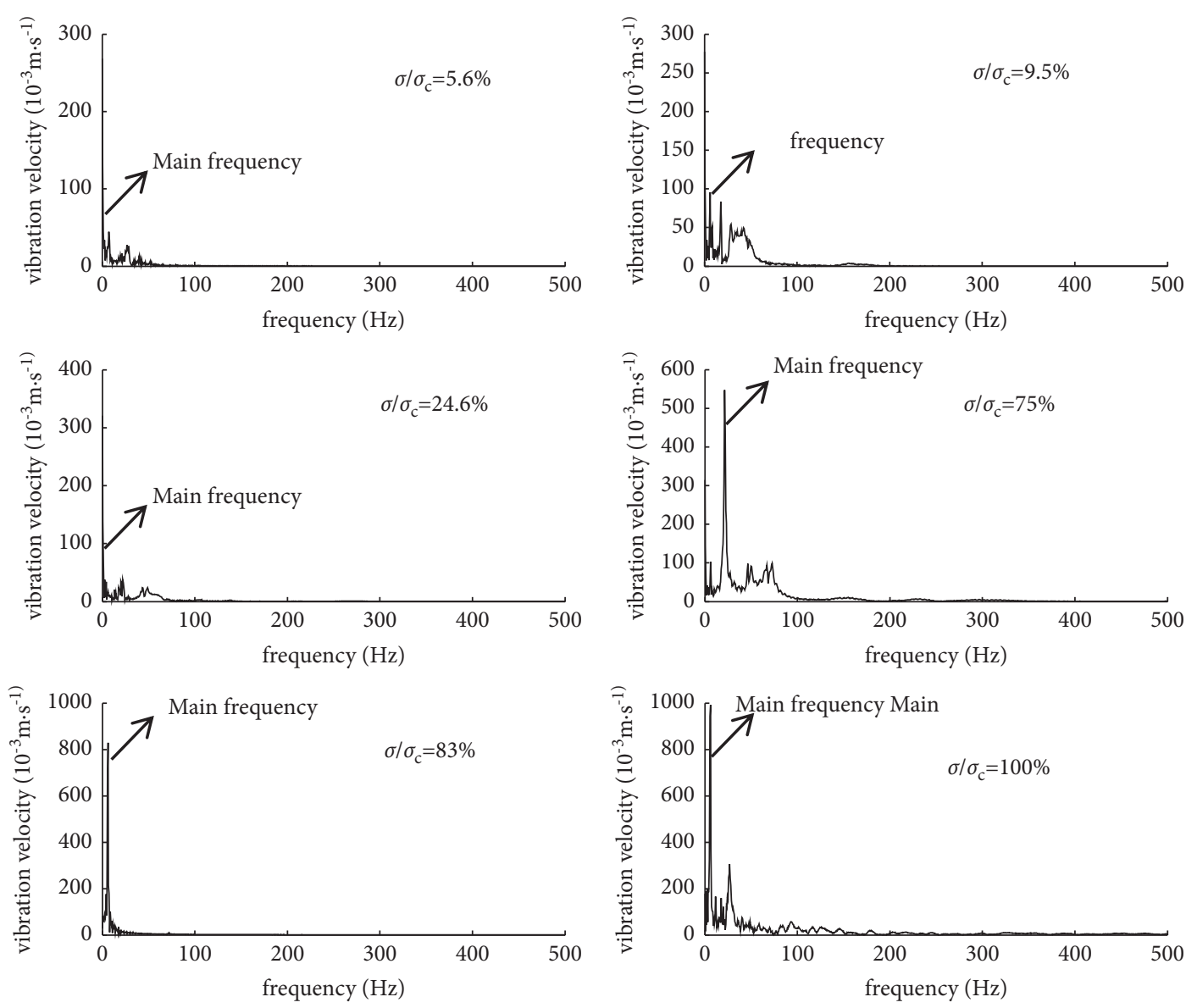

Figure 8: Microseismic signals spectrum of sandstone in different stages when loading rate is $0.01 \mathrm{~mm} / \mathrm{s}$.

during loading is more complex than that of microseismic signals. Any section of the charge signals is generated by a combination of fracture tip discharge, frictional misalignment of the joint surface, and piezoelectric effects, but for a specific time, the charge signals are mainly generated by one or two dominant factors. In contrast, microseismic signals are generated for a relatively single reason and can be generated at high amplitude whenever energy is released by rock destroyed. However, if no destruction occurs to the rock, the strain energy absorbed during loading is not released, and no high-amplitude microseismic signals are generated even when the postpeak softening stage is reached.

Analysis of the experimental data also revealed that the occurrence of stress drop in the coal rock is a sufficient and nonessential condition for the generation of charge induction and microseismic signals. Stress drop must generate a high-amplitude pulse signal, but a high-amplitude pulse signal does not necessarily mean that a stress drop has occurred for reasons that remain to be explored. The author believes that it is not feasible to analyze only the signal pattern or to measure only the stress change in the surrounding rock as a precursor criterion in the field. There is a potential for misjudgment. Therefore, a specific analysis is needed in combining the signals obtained from monitoring and the distribution of stress fields in the rock monitoring area.
3.3. Analysis of Microseismic Signals Spectrum of Coal and Rock. The spectrum of microseismic signals changes during the deformation and failure of coal and rock. Fourier spectrum analysis (FFT) is used to analyze the spectrum of microseismic signals. Figures 8 and 9 show the spectrum of microseismic signals in the vertical direction when the loading rates of sandstone samples are $0.01 \mathrm{~mm} / \mathrm{s}$ and $0.05 \mathrm{~mm} / \mathrm{s}$, respectively. Figure 10 shows the spectrum of microseismic signals in the vertical direction when the loading rates of coal samples are $0.01 \mathrm{~mm} / \mathrm{s}$. In the figure, $\sigma / \sigma_{c}$ is the stress level at the trigger time of each event.

It can be seen from Figures 8-10 that the dominant frequency of microseismic signal changes continuously in the deformation and fracture process of coal and rock samples. At the initial stage of loading, the specimen is in the compaction stage, and there are a large number of cracks and pores in the rock mass. With the load increase, the cracks and pores will be closed, and small microseismic events will be generated. The dominant frequency is $0-10 \mathrm{~Hz}$, and the amplitude of microseismic signal spectrum is also small. When the samples are in the early and middle stages of strengthening damage, the deformation and fracture of the rock mass are paroxysmal and discontinuous. Only when the deformation in the rock mass exceeds the energy required for the microfracture of the sample, the fracture will be caused, and the elastic energy will be released to produce 

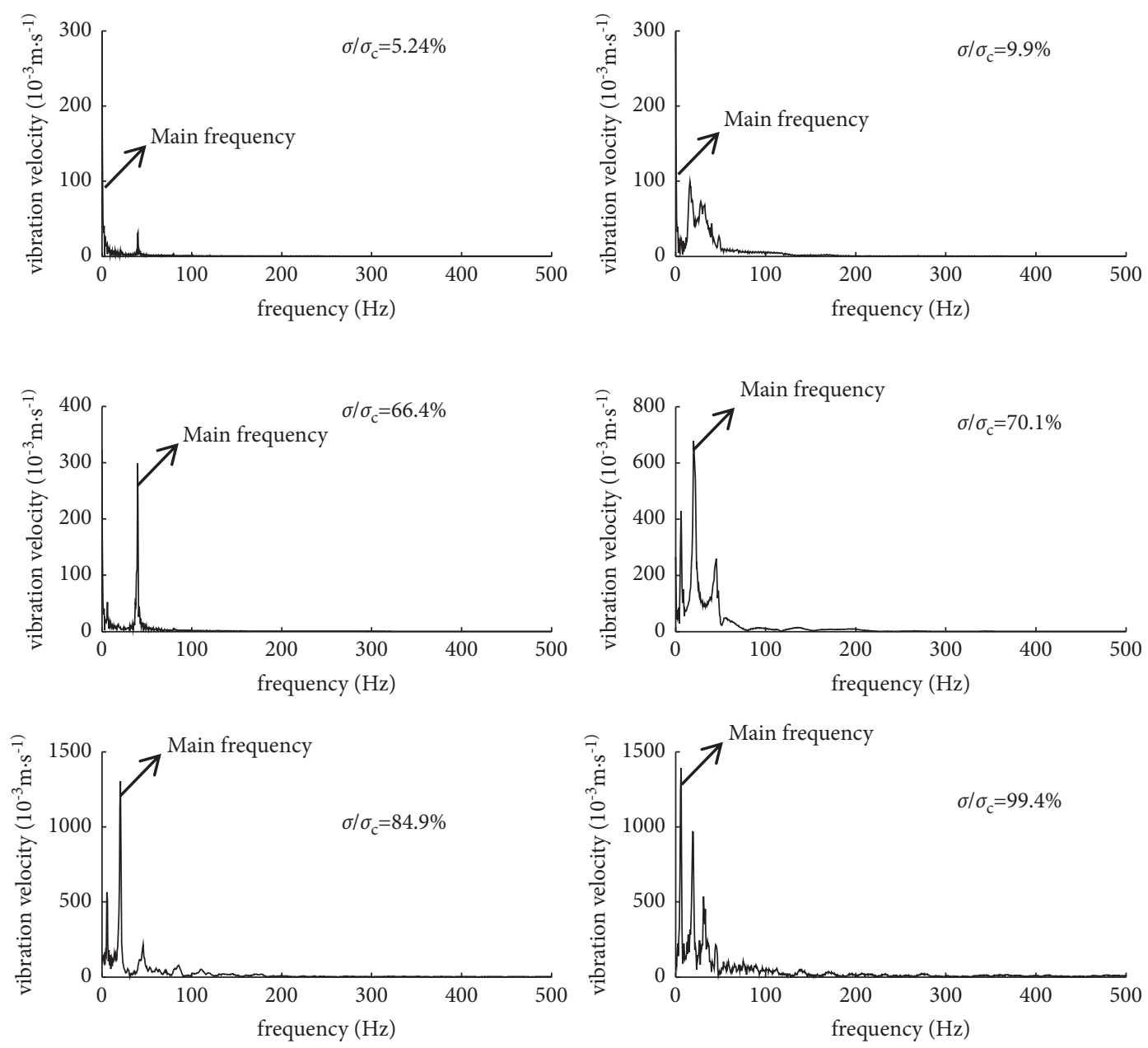

FIgURE 9: Microseismic signals spectrum of sandstone in different stages when the loading rate is $0.05 \mathrm{~mm} / \mathrm{s}$.

microseismic signals. At this stage, because of the increase of stress, the deformation and fracture of the sample will increase, the intensity of microseismic signals will increase, the dominant frequency and amplitude will increase, highfrequency microseismic signals will increase, and the main frequency will be $20-100 \mathrm{~Hz}$. When the samples are in the later stages of strengthening damage, a large number of microcracks have been formed in the rock mass. With the increase of load, the samples' deformation is accelerated, and the microcracks in the rock begin to converge and penetrate. Keeping constant load at this stage, the samples' deformation will also be generated. At this stage, the number and amplitude of microseismic events increase, and the frequencies of microseismic signals generated by the convergence, penetration, and fracture of different fractures are different. Therefore, the main frequency band becomes wider, and there is the secondary main frequency. The spectrum is centrally distributed at $0-100 \mathrm{~Hz}$ and has the characteristics of high value. When the samples are in the postpeak stage, the spectrum amplitude of microseismic signals is the largest, and the high-frequency microseismic signals are the most. With the increase of specimen stress, the dominant frequency of microseismic signals first increases and then decreases, while the amplitude of the dominant frequency increases synchronously. The amplitude of microseismic signals' dominant frequency is the largest in instability failure. With the increase of loading rate, the spectrum amplitude of microseismic signals changes little in the compaction stage, but the spectrum amplitude increases in other stages. At the same loading speed, the events' number of microseismic signals of coal samples after peak stress is more than that of sandstone samples, and the signal amplitude is also larger. However, the spectrum distribution range of microseismic signals of coal samples is wider than that of sandstone samples, and the spectrum amplitude of coal samples is lower than that of sandstone.

3.4. Charge Induction and Microseismic Energy Analysis. Figure 11 shows the mean square energy of 6-channel microseismic and 2-channel charge signals of the sandstone at different loading rates. The energy release of specimens is consistent with the stress drop under different loading rates. At a low loading rate, there is almost no energy release before the peak of the sandstone sample, and the events' number of energy release after the peak stress is small. The longest energy release duration of the microseismic signal is $1.3 \mathrm{~s}$, the longest energy release duration of the charge signal is $0.4 \mathrm{~s}$, the highest amplitude of microseismic signal mean 

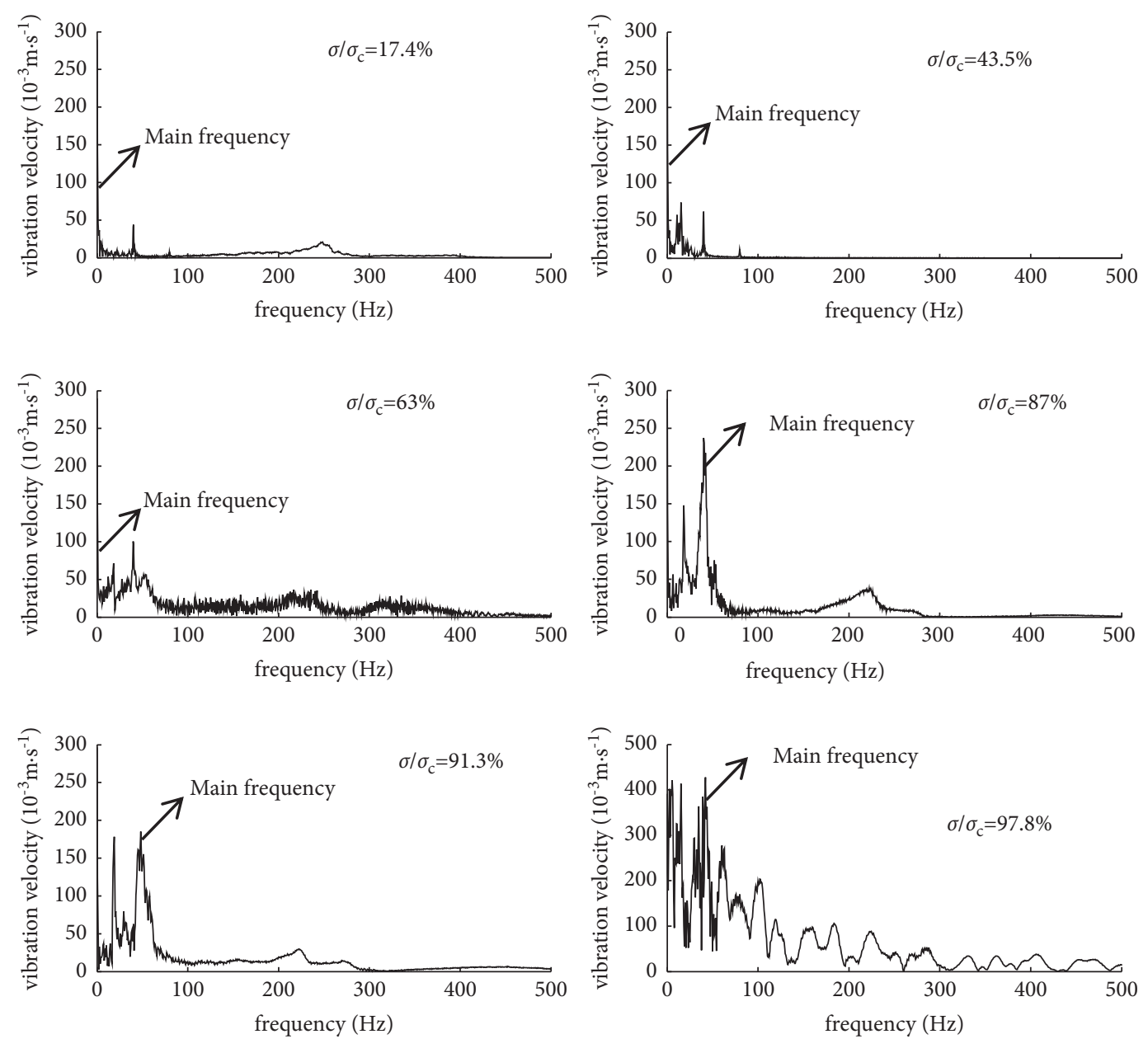

FIGURE 10: Microseismic signals spectrum of coal in different stages when the loading rate is $0.01 \mathrm{~mm} / \mathrm{s}$.
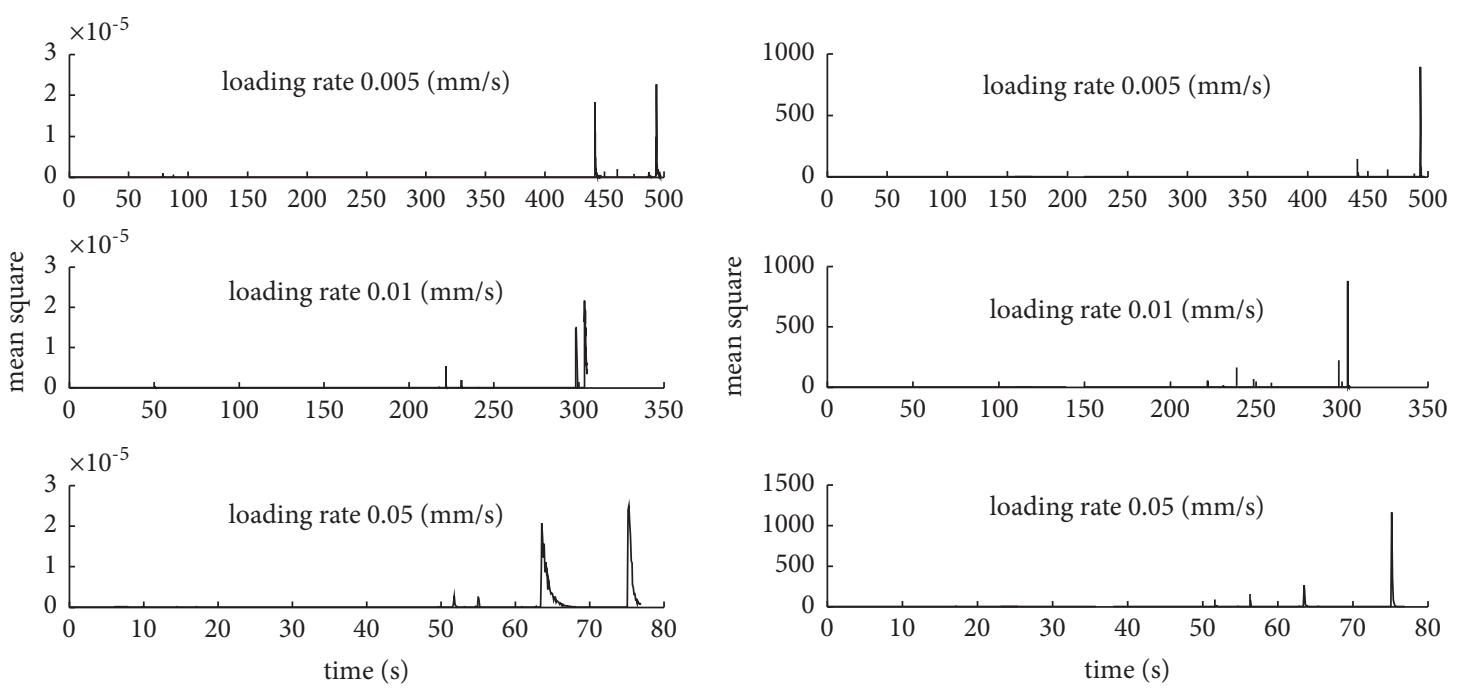

(a)

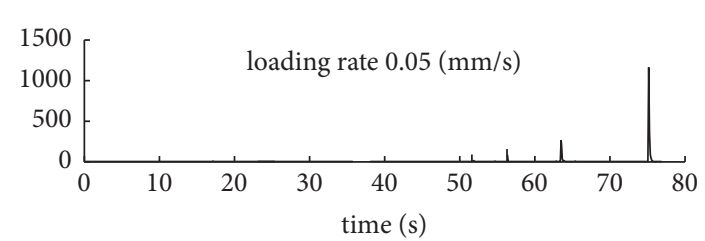

(b)

FIGURE 11: Mean square energy of microseismic and charge signals of sandstones at different loading rates. (a) Microseismic. (b) Charge induction. 
square is $2.27 \times 10^{-5}$, and the maximum amplitude of charge signal mean square is 918 . At a high loading rate, the energy release events with obvious amplitude begin to appear in the middle of the loading stage of the sandstone sample. The longest energy release duration of the microseismic signal is $4.5 \mathrm{~s}$, the longest energy release duration of the charge signal is $0.6 \mathrm{~s}$, the highest amplitude of the microseismic signal mean square is $2.5 \times 10^{-5}$, and the maximum amplitude of charge signal mean square is 1216 . With the increase of loading rate, the time with a high-amplitude signal for the first time is advanced, and the specimen stress becomes lower when the high-amplitude signal is generated for the first time. With the increase of loading rate, the duration of microseismic and charge signal is longer, and the mean square amplitude of charge signal is larger.

\section{Summary and Discussion}

The compressive strength of coal and rock increases with the increase of loading rate. The stress decreases when the specimen is in the strengthening damage stage. In the strengthening damage stage, the stress growth rate of the specimen accelerates. The time from the peak stress to instability failure of the specimen becomes shorter, and the strain becomes smaller. At the same loading speed, the postpeak softening failure stage of coal lasts longer than that of sandstone. The coal samples are destroyed quickly when the stress reaches the peak stress at the loading rate of $0.05 \mathrm{~mm} / \mathrm{s}$, while the sandstone is destroyed quickly when the stress reaches the peak stress at the loading rate of $0.01 \mathrm{~mm} / \mathrm{s}$.

With the increase of loading rate, the time of the first obvious electric charge and microseismic signals for the coal and rock is advanced, and the duration of charge induction and microseismic signal is longer. The events' number and the amplitude of charge signal and microseismic signal are increased. Before the instability failure, the charge-induced signal and microseismic signal have both synchronous and asynchronous signals, and the amplitude of charge-induced and microseismic signals in each channel is different, which is related to the distance from the position of each sensor to the fracture point of the sample. During the instability failure, the charge induction and microseismic signals of each channel are generated synchronously, and the signal amplitude reaches the maximum values of $50 \mathrm{pC}$ and $6 \times 10^{-3} \mathrm{~m} / \mathrm{s}$ at the same time.

With the increase of specimen stress, the dominant frequency of microseismic signals first increases and then decreases, while the amplitude of dominant frequency increases synchronously. The dominant frequency amplitude of microseismic signals is the largest in instability failure. With the increase of loading rate, the spectrum amplitude of microseismic signals changes little in the compaction stage, but the spectrum amplitude increases in other stages. At the same loading speed, the events' number of microseismic signal of coal samples after peak stress is more than that of sandstone samples, and the signal amplitude is also larger. However, the spectrum distribution range of microseismic signal of coal samples is wider than that of sandstone samples, and the spectrum amplitude of coal samples is lower than that of sandstone.

With the increase of loading rate, the time with a highamplitude signal for the first time is advanced, and the specimen stress becomes lower when the high-amplitude signal is generated for the first time. With the increase of loading rate, the duration of microseismic and charge signal is longer, and the mean square amplitude of charge signal is larger.

\section{Data Availability}

The data used to support the findings of this study are included within the article.

\section{Conflicts of Interest}

The authors declare that they have no conflicts of interest.

\section{Acknowledgments}

This research was supported by the General Programs of the National Natural Science Foundation of China (Grant nos. 52074142, 51974150, and 51274114) and the University Innovation Talent Support Program of Liaoning Province (Grant no. LR2019032).

\section{References}

[1] Y. S. Pan, Z. H. Li, and M. T. Zhang, "Distribution, type, mechanism and prevention of rockburst in China," Chinese Journal of Rock Mechanics and Engineering, vol. 11, pp. 1844-1851, 2003.

[2] Y. F. Zhao, Y. S. Pan, Y. C. Liu, and Y. Zhu, "Experimental study of charge induction of coal samples under uniaxial compression," Chinese Journal of Rock Mechanics and Engineering, vol. 30, no. 2, pp. 306-312, 2011.

[3] X. Liu, S. Song, Y. Tan et al., "Similar simulation study on the deformation and failure of surrounding rock of a large section chamber group under dynamic loading," International Journal of Mining Science and Technology, vol. 31, no. 3, pp. 495-505, 2021.

[4] X. S. Liu, D. Y. Fan, Y. L. Tan et al., "New detecting method on the connecting fractured zone above the coal face and a case study," Rock Mechanics and Rock Engineering, vol. 54, pp. 4379-4391, 2021.

[5] Y. F. Zhao, L. Q. Liu, Y. S. Pan, and B. Jiao, "Experiment study on microseismic, charge induction, self-potential and acoustic emission during fracture process of rocks," Chinese Journal of Rock Mechanics and Engineering, vol. 36, no. 1, pp. 107-123, 2017.

[6] Y. Q. Zhu, X. L. Luo, Z. Q. Guo, and Z. Zhao, "A study of mechanism on electromagnetic emission associated with rock fracture," Acta Geophysica Sinica, vol. 34, no. 5, pp. 594-601, 1991.

[7] V. S. Kuksenko and K. F. Makhmudov, "Mechanically-induced electrical effects in natural dielectrics," Technical Physics Letters, vol. 23, no. 2, pp. 126-127, 1997.

[8] V. S. Kuksenko, K. F. Makhmudov, and A. V. Ponomarev, "Relaxation of electric fields induced by mechanical loading in natural dielectrics," Physics of the Solid State, vol. 39, no. 7, pp. 1065-1066, 1997. 
[9] E. Y. Wang, X. F. Liu, and X. Q. He, "Acoustic emission and electromagnetic radiation synchronized monitoring technology and early-warning application for coal and rock dynamic disasters," Journal of China University of Mining and Technology, vol. 47, no. 5, pp. 942-948, 2018.

[10] Y. S. Pan, Z. Tang, Z. H. Li, L. Y. Zhu, and G. Z. Li, "Research on the charge inducing regularity of coal rock at different loading rate in uniaxial compression tests," Chinese Journal of Geophysics, vol. 56, no. 3, pp. 1043-1048, 2013.

[11] Y. S. Pan, H. Luo, and X. C. Xiao, "Experimental study on mechanical-charge induction law of coal containing gas under triaxial compression," Journal of China Coal Society, vol. 37, no. 6, pp. 918-922, 2012.

[12] Y. S. Pan, H. Luo, Z. Tang, and Z. Li, "Study of charge induction law of coal and rock mass during tensile instability and failure," Chinese Journal of Rock Mechanics and Engineering, vol. 32, no. 7, pp. 1297-1303, 2013.

[13] F. He, Z. W. Wang, Y. F. Zhao, G. Song, and B. Liu, "Experimental investigations on electrical charge of pre-cracked rock specimens under uniaxial compression," Shock and Vibration, vol. 2020, Article ID 8861030, 2020.

[14] Y. N. Li, E. Y. Wang, and E. L. Zhao, "Experiment on surface potential of coal under uniaxial compression," Journal of China Coal Society, vol. 34, no. 6, pp. 806-809, 2009.

[15] Z. H. Li, E. Y. Wang, and Z. T. Liu, "Study on characteristics and rules of surface potential during coal fracture," Journal of China University of Mining and Technology, vol. 38, no. 2, pp. 187-192, 2009.

[16] Z. H. Li, E. Y. Wang, X. Y. Song, and S. Hu, "Study on strain localization and surface potential distribution law of coal samples fracturing," Journal of China Coal Society, vol. 37, no. 12, pp. 2034-2047, 2012.

[17] Y. L. Yang, Z. H. Li, E. Y. Wang, and Y. Zhu, "Experiment study on surface potential characteristics and rules during coal or rock friction process," Journal of China Coal Society, vol. 38, no. 2, pp. 215-220, 2013.

[18] X. Y. Xu, E. Y. Wang, and F. L. Xu, "Micro-seismic frequency spectrum of coal rock under uniaxial compression," Applied Acoustics, vol. 29, no. 2, pp. 148-153, 2010.

[19] Y. J. Yang, Basic Experimental Study on Characteristics of Strength, Deformation and Microseismic of Coal under Compression, Shandong University of Science and Technology, Taian, Shandong, China, 2006.

[20] X. N. Wang, C. P. Lu, J. H. Xue, and J. Zhang, "Experimental research on rules of acoustic emission and micro seismic effects of burst failure of compound coal-rock samples," Rock and Soil Mechanics, vol. 34, no. 9, pp. 2569-2575, 2013.

[21] C. W. Li, X. Y. Sun, T. B. Gao, and B. Xie, "Coal and rock vibration failure and the characteristics of micro-seismic signals," Journal of China Coal Society, vol. 40, no. 8, pp. 1834-1844, 2015.

[22] Q. J. Zhu, Q. S. Li, S. Q. Li, and Z. Han, "Microseismic dynamic response and characteristic analysis of coal and gas outburst experiment," Chinese Journal of Rock Mechanics and Engineering, vol. 34, no. S2, pp. 3813-3821, 2015. 